\title{
Body composition and pulmonary function in cystic
}

\section{fibrosis}

\author{
Saba Sheikh ${ }^{1,2 *}$, Babette S. Zemel ${ }^{2,3}$, Virginia A. Stallings ${ }^{2,3}$, Ronald C. Rubenstein ${ }^{1,2 *}$ and Andrea Kelly $y^{2,4}$ \\ ${ }^{1}$ Division of Pulmonary Medicine, Cystic Fibrosis Center, Perelman School of Medicine at the University of Pennsylvania, Philadelphia, PA, USA \\ ${ }^{2}$ Department of Pediatrics, Perelman School of Medicine at the University of Pennsylvania, Philadelphia, PA, USA \\ ${ }^{3}$ Division of Gastroenterology, Hepatology and Nutrition, Perelman School of Medicine at the University of Pennsylvania, Philadelphia, PA, USA \\ ${ }^{4}$ Division of Endocrinology and Diabetes, The Children's Hospital of Philadelphia, Philadelphia, PA, USA
}

Edited by:

Luis Garcia-Marcos, University of

Murcia, Spain

\section{Reviewed by:}

Manuel Sanchez-Solis, University

Hospital Virgen de la Arrixaca, Spain

Luis Garcia-Marcos, University of

Murcia, Spain

\section{*Correspondence:}

Saba Sheikh and Ronald C.

Rubenstein, Division of Pulmonary

Medicine and Cystic Fibrosis Center,

The Children's Hospital of

Philadelphia, Perelman School of

Medicine at the University of

Pennsylvania, 34th Street, Civic

Center Blvd., Philadelphia, PA 19104

USA

e-mail:sheikhs@email.chop.edu

rrubenst@mail.med.upenn.edu
Background: Lower body mass index (BMI) is associated with worse pulmonary function in cystic fibrosis (CF). Hypothesis: lean body mass (LBM) is more strongly associated with pulmonary function than $\mathrm{BMI}$ is.

Methods: Anthropometrics, body composition by dual x-ray absorptiometry, and pulmonary function were determined in pancreatic insufficient CF (PI-CF) youth. Sex and age-adjusted $Z$-scores (BMI-Z, LBMI-Z, FMI-Z) were generated for CF and controls. (1) Associations of BMI- $Z$ with LBMI- $Z$ and $\mathrm{FMI}-Z$ and (2) age-adjusted associations of BMI- $Z$, LBMI- $Z$, and $\mathrm{FMI}-Z$ with $\mathrm{FEV}_{1} \%$-predicted were tested.

Results: Two hundred eight PI-CF subjects had lower BMI-Z, LBMI-Z, and FMI-Z compared to 390 controls. BMI- $Z$ was associated with lower LBMI- $Z(p<0.0001)$ in PI-CF. In females, $\mathrm{LBMI}-Z$ and $\mathrm{BMI}-Z$ were positively associated with $\mathrm{FEV}, \%$-predicted; this relationship did not persist for $\mathrm{FMI}-Z$ after adjustment for LBMI-Z. In males, only LBMI- $Z$ and BMI- $Z$ were associated with $\mathrm{FEV}_{1} \%$-predicted.

Conclusion: In PI-CF youth, deficits in LBM were apparent. At lower BMI percentiles, BMI may not accurately depict LBM in PI-CF. In under-nourished PI-CF youth, this preservation of $\mathrm{FM}$ in preference to LBM is relevant since LBMI- $Z$, but not $\mathrm{FMI} Z$, is positively associated with $\mathrm{FEV}_{1} \%$-predicted. Lean body mass index is more strongly associated with lung function compared to BMI, especially in the under-nourished child and adolescent with PI-CF.

Keywords: body mass index, lean body mass, fat mass index, lean body mass index, pancreatic insufficient

\section{INTRODUCTION}

Stature, weight, and body mass index (BMI) are typically used to assess nutritional status in cystic fibrosis (CF) since these measures are obtained in clinical practice and reference data are available. Moreover, since poor nutritional status is associated with worse pulmonary function in CF (1-3), the CF foundation (CFF) clinical care guidelines set a goal to maintain BMI above 50th percentile in children and above 22 or 23 in adults with CF in order to support optimal pulmonary function (4).

The association of higher BMI with better pulmonary function in CF is hypothesized to reflect the impact of lean body mass (LBM) upon respiratory muscle strength and physical wellbeing $(5,6)$. However, in the general population, BMI is used to indicate body fatness. Studies directly measuring body composition in CF are limited $(5,7,8)$. Their results are difficult to generalize in children and adolescents with CF due to inclusion of adults, differing body composition methodologies, small sample sizes, and variability in the degree of malnutrition and pulmonary disease in the subject cohorts. Lower fat free mass (FFM), a measure of both bone and muscle mass derived from dual x-ray absorptiometry (DXA), indirectly estimates LBM and has been associated with lower $\mathrm{FEV}_{1} \%$-predicted and more frequent pulmonary exacerbations in adults with CF (9-11). Adults with unrecognized FFM depletion, defined as normal BMI and low FFM, have lower $\mathrm{FEV}_{1} \%$-predicted than adults with both normal BMI and normal FFM (12). This finding highlights the limitation of BMI as an informative marker of nutritional status in complex chronic diseases such as CF (5). Similarly, DXA-derived LBM, which estimates non-bone LBM, was correlated with degree of lung function impairment in adults and with clinical severity score in both children and adults in studies with small sample sizes (7, 13). In contrast, Williams et al. (14) studied body composition in 6- to 12-year-olds with PI-CF using a four-compartment model, a technique limited to the research setting. Their study found that girls with PI-CF had a significantly lower fat mass (FM) compared to age-, height-, and puberty-matched controls, and that FM was positively associated with $\mathrm{FEV}_{1} \%$-predicted. This association was not significant in males and no association was seen with FFM in this cohort.

The extent to which worse nutritional status directly contributes to worse pulmonary function has not been fully delineated. Given the emphasis placed upon optimizing nutritional 
status in CF clinical care, interventions aimed at improving BMI, and an emergence of obesity (15) in children and adults with CF, an improved understanding of body composition especially fat compared to muscle stores in CF health is indicated. The aim of this study was to assess the associations of BMI and DXA-derived measures of LBM and FM with lung function in a population of children and adolescents with pancreatic insufficient CF (PICF) without significant CF-related morbidities. We hypothesized that the association of BMI and pulmonary function reflects the association of LBM and pulmonary function.

\section{MATERIALS AND METHODS \\ SUBJECTS}

Individuals with PI-CF, aged 5-21 years were recruited from the Cystic Fibrosis Centers at The Children's Hospital of Philadelphia, Philadelphia, PA, USA, the Hospital of the University of Pennsylvania, Philadelphia, PA, USA, and multiple other CF Centers in the United States (refer to acknowledgments). Data were collected during the period from November 2000 to February 2002 for a study on bone mineral content (16) and then again at baseline in a separate cohort during a clinical trial from March 2007 to May 2011. The diagnoses of CF and pancreatic insufficiency were based upon CFF recommendations.

Inclusion criteria included an $\mathrm{FEV}_{1} \%$-predicted $>40 \%$. Subjects were excluded for diabetes, cirrhosis or portal hypertension, history of lung or liver transplant, or presence of other medical conditions not associated with CF that could potentially affect growth.

A group of 390 healthy Caucasian children and young adults, aged 5-21 years were selected from the Philadelphia area as a control group (16). A separate group of 462 non-African American subjects were evaluated at our center to generate contemporary reference data for growth and body composition (17); standard deviation scores for CF subjects and healthy controls were generated from these reference data.

For CF subjects, medical records were reviewed and data were collected for genotype. CF genotype was categorized as homozygous for $\triangle F 508$ mutation, compound heterozygous with one $\Delta \mathrm{F} 508$ allele, or other variants.

\section{ANTHROPOMETRY}

Weight was measured using a digital scale (Scaltronix, White Plains, NY, USA). Height was measured using a stadiometer (Holtain, Crymych, UK). BMI (weight/height ${ }^{2}$ ) was calculated. Age- and sex-adjusted $Z$-scores for height, weight, and BMI were calculated using current reference data (18).

\section{PUBERTY STAGING}

Puberty status was ascertained using a validated self-assessment questionnaire to categorize Tanner stages (TS) of pubic hair distribution (both sexes), and either genital development (males) or breast development (females) (19).

\section{DUAL ENERGY X-RAY ABSORPTIOMETRY}

Spine and whole body DXA scans were acquired using a fan beam array (Hologic Delphi, Bedford, MA, USA), and analyzed using the Discovery software (version 12.3). Whole body scans were analyzed to generate estimates of LBM (kilogram) and FM (kilogram).

Lean body mass index $\left(\mathrm{LBMI}=\mathrm{LBM} /\right.$ height $\left.^{2}\right)$ and fat mass index $\left(\mathrm{FMI}=\mathrm{FM} /\right.$ height $\left.^{2}\right)$ were calculated for the CF and controls. Age-based reference curves were generated for males and females from 462 healthy subjects using the lambda-mu-sigma (LMS) method (20). LBMI and FMI were then converted to sexand age-adjusted $Z$-scores for the $\mathrm{CF}$ and controls using these contemporary reference data.

\section{SPIROMETRY}

To assess pulmonary function, standard spirometry was performed by subjects with $\mathrm{CF}$. $\mathrm{FEV}_{1}$ was reported as the percentage of predicted value $\left(\mathrm{FEV}_{1} \%\right.$-predicted) based upon prediction equations of Wang and Hankinson $(21,22)$. Forced vital capacity (FVC) was similarly reported as percentage of predicted value (FVC\%-predicted).

\section{STATISTICAL ANALYSES}

Continuous variables were summarized using mean, median, and standard deviation, and categorical variables were described using proportions. Means for normally distributed data including age, $\mathrm{FEV}_{1} \%$-predicted, FVC\%-predicted, BMI- $Z$, LBMI- $Z$, and FMI- $Z$ were compared using two-sided $t$-test; $p<0.05$ was considered statistically significant.

Linear regression was used to compare the relationships between BMI- $Z$ and (1) LBMI- $Z$ and (2) FMI- $Z$ in CF and controls; since the relationship between BMI- $Z$ and FMI$Z$ is non-linear, BMI- $Z$ squared was included in the FMI- $Z$ model. The interaction between BMI- $Z$ and CF status was also assessed.

The analyses were stratified by sex and multiple linear regression was used to assess the associations between body composition (BMI- $Z$, LBMI- $Z$, and FMI- $Z$ ) and pulmonary function $\left(\mathrm{FEV}_{1} \%\right.$ predicted and $\mathrm{FVC} \%$-predicted). These associations were tested individually and in combined models. The fit of each model was evaluated by comparing the adjusted $R^{2}$, likelihood ratio, and Akaike information criterion (AIC). Models were adjusted for age and age squared to account for the known age-related decline in pulmonary function. The effects of puberty [pre-pubertal (Tanner 1) vs. pubertal (Tanner 2-5)], race/ethnicity, type of CFTR mutation, and colonizing pathogens in sputum culture on these associations were tested. To test for effect modification by nutritional status, subjects were also categorized by BMI, acceptable $(\mathrm{BMI} \geq 50$ th\%o $)$ vs. sub-optimal BMI (<50th\%o) (4).

The ability of BMI- $Z<0$ vs. LBMI- $Z<0$ to identify subjects with $\mathrm{FEV}_{1} \%$-predicted $\geq 80$ and $<80 \%$ adjusted for age and sex was compared using logistic regression.

Regression diagnostics were performed on all models through graphical checks, the Shapiro-Wilk test of normality of the residuals, and the Cook-Weisberg test for heteroscedasticity. All analyses were performed using STATA 12 (StataCorp LP, College Station, TX, USA).

The Institutional Review Boards at each of the participating institutions approved the study protocols, under which these data were collected. Informed consent or assent was obtained as appropriate. 
Table 1 | Characteristics of subjects (mean \pm SD).

\begin{tabular}{|c|c|c|c|c|c|c|}
\hline & \multicolumn{3}{|c|}{ Males } & \multicolumn{3}{|c|}{ Females } \\
\hline & $\mathrm{CF}(n=111)$ & Controls $(n=182)$ & $p$-Value & CF $(n=97)$ & Controls $(n=208)$ & $p$-Value \\
\hline Age & $12.3 \pm 3.6$ & $11.7 \pm 3.6$ & 0.22 & $12.5 \pm 4.1$ & $12.1 \pm 3.5$ & 0.35 \\
\hline HT-Z & $-0.46 \pm 0.91$ & $0.18 \pm 0.86$ & $<0.0001$ & $-0.46 \pm 0.99$ & $0.19 \pm 0.82$ & $<0.0001$ \\
\hline WT-Z & $-0.51 \pm 0.90$ & $0.24 \pm 0.89$ & $<0.0001$ & $-0.44 \pm 0.95$ & $0.27 \pm 0.80$ & $<0.0001$ \\
\hline BMI-Z & $-0.33 \pm 0.83$ & $0.16 \pm 0.96$ & $<0.0001$ & $-0.20 \pm 0.88$ & $0.23 \pm 0.84$ & 0.0001 \\
\hline LBMI-Z & $-0.63 \pm 0.94$ & $0.01 \pm 1.0$ & $<0.0001$ & $-0.56 \pm 1.00$ & $0.01 \pm 0.97$ & $<0.0001$ \\
\hline FMI-Z & $-0.37 \pm 0.87$ & $0.00 \pm 1.0$ & 0.0016 & $-0.39 \pm 1.00$ & $-0.02 \pm 0.99$ & 0.003 \\
\hline $\mathrm{FEV}_{1} \%$ & $90 \pm 20$ & $\mathrm{NA}^{a}$ & - & $88 \pm 21$ & NA & - \\
\hline FVC\% & $96 \pm 18$ & NA & - & $91 \pm 21$ & NA & - \\
\hline \multicolumn{7}{|l|}{ Race } \\
\hline Caucasian & $101(91 \%)$ & 182 (100\%) & & $85(88 \%)$ & $208(100 \%)$ & \\
\hline Other & $9(8 \%)$ & 0 & & $8(8 \%)$ & 0 & \\
\hline Unknown & $1(1 \%)$ & 0 & & $4(4 \%)$ & 0 & \\
\hline Pubertal/pre-pubertal & $75 / 36$ & $113 / 69$ & 0.88 & $73 / 24$ & $154 / 54$ & 0.47 \\
\hline
\end{tabular}

\section{RESULTS}

\section{POPULATION CHARACTERISTICS}

Characteristics for subjects with CF and PI are summarized in Table 1. A total of 211 subjects (114 males, 97 females), aged 521 years with PI-CF were evaluated. Spirometry was not available for three subjects. Data from the remaining 208 subjects were analyzed. Consistent with the known genetic epidemiology of CF, the majority $(90 \%)$ were Caucasian, and $72 \%$ had at least one $\Delta \mathrm{F} 508$ CFTR mutation.

Males and females with CF were similar in age, and the various pubertal stages were well-represented in both sexes. Mean growth and body composition $Z$-scores were all $<0$ in the CF population. No sex differences in weight- $Z$, height- $Z$, BMI- $Z$, LBMI- $Z$, and FMI- $Z$ overall, or within puberty groups (pre-pubertal or pubertal) were identified (data not shown).

Lean body mass index- $Z$ was positively associated with height$Z(p<0.0001)$ but the relationship was attenuated in the setting of CF $(p<0.0001)$. LBMI- $Z$ was also positively associated with weight- $Z(p<0.0001)$ with a minor interaction between weight$Z$ and CF status $(p=0.06)$ such that for a given weight- $Z$, CF subjects have a lower LBMI- $Z$ compared to controls. Similarly, LBMI- $Z$ was positively associated with BMI- $Z$ in both CF and controls, but this positive relationship was attenuated in the setting of CF $(p<0.0001$, Figure 1A and Table 2), even after adjustment for puberty. Moreover, CF subjects with “sub-optimal” BMI $(n=131)$ had lower mean LBMI- $Z$ compared to controls with BMI $<50 \%$ $(n=154)(p=0.006)$.

The positive association between FMI- $Z$ and height- $Z$ was blunted in the presence of CF ( $p=0.001)$. In contrast, the positive relationship of FMI- $Z$ with weight- $Z$ and weight- $Z$ squared was magnified in the presence of CF $(p=0.024)$. FMI- $Z$ was positively associated with BMI- $Z(p<0.0001)$ in CF and controls (Table 2) after adjustment for puberty, but the relationship was not altered by the presence of CF (Figure 1B).

\section{PULMONARY FUNCTION AND BODY COMPOSITION}

Cystic fibrosis subjects had a mean $\mathrm{FEV}_{1} \%$-predicted $89 \pm 21$, and a mean $\mathrm{FVC} \%$-predicted $96 \pm 19$. No difference in pulmonary function was found between males and females with CF $(p=0.41)$. Increasing age was associated with lower $\mathrm{FEV}_{1} \%$-predicted $(\beta$ coefficient $\left.=-2.1, \mathrm{CI}:-2.8,-1.4, p<0.0001, R^{2}=0.15\right)$. This negative association was more pronounced in females than males (decrease in $\mathrm{FEV} 1 \%$ of 2.7 vs. $1.4 \%$ for each 1 year increase in age).

\section{Females}

After adjusting for age, BMI- $Z$ ( $p=0.001)$, LBMI- $Z(p<0.0001)$, and FMI- $Z$ (0.046) were all positively associated with $\mathrm{FEV}_{1} \%$ predicted in females (Figure 2; Table 3). The relationship was strongest with LBMI- $Z$ (lowest AIC), and the association of FMI- $Z$ with $\mathrm{FEV}_{1} \%$-predicted was no longer significant when included in the model with LBMI- $Z(p=0.96)$. Pubertal status did not alter the relationship of body composition and $\mathrm{FEV}_{1} \%$ predicted $(p=0.10)$. The relationship between LBMI- $Z$ and $\mathrm{FEV}_{1} \%$-predicted was modified by nutritional status: in the setting of "acceptable" BMI- $Z(\geq 0)$ the effect of increasing LBMI- $Z$ on $\mathrm{FEV}_{1} \%$-predicted was blunted (partial $\beta$-coefficient $=-11.9$; $p=0.008)$.

Moreover, after adjustment for age, females with "acceptable" LBMI- $Z$ ( $Z \geq 0$ or LBMI $\geq 50$ th\%o) were five times more likely to have an $\mathrm{FEV}_{1} \%$-predicted $>80 \%$ than females with low LBMI- $Z(<0)(\mathrm{OR}=5.1, p=0.016)$ while females with acceptable BMI- $Z$ ( $\geq 0$ or $\mathrm{BMI} \geq 50$ th\%o) were about six times more likely to have an $\mathrm{FEV}_{1} \%$-predicted $>80 \%(\mathrm{OR}=6.3, p=0.002)$ (Table 3).

Body mass index- $Z$ was positively associated with ageadjusted FVC\%-predicted in females (partial $\beta$-coefficient $=4.6$, $p=0.046$ ). Similarly, after adjustment for age, LBMI- $Z$ was positively associated with $\mathrm{FVC} \%$-predicted ( artial $\beta$-coefficient $=5.5$, $p=0.004)$. In contrast, FMI- $Z$ was not associated with FVC\%predicted $(p=0.11)$.

\section{Males}

As shown in Figure 2 and Table 3, BMI- $Z(p<0.0001)$ and LBMI- $Z(p<0.0001)$, but not FMI- $Z$, were positively associated with $\mathrm{FEV}_{1} \%$-predicted after adjustment for age in males. Based 

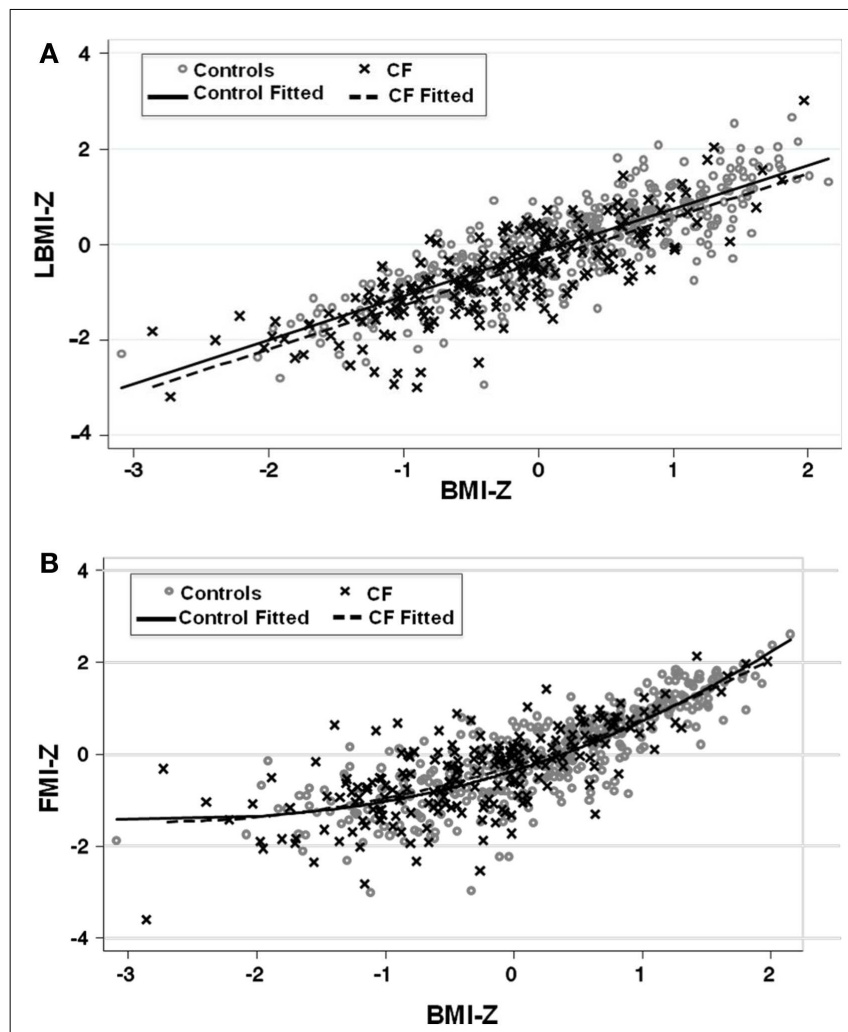

FIGURE 1 | (A) The association between LBMI- $Z$ and BMI- $Z$ among healthy controls and patients with CF. There is a positive association between LBMI- $Z$ and $\mathrm{BMI}-Z$ in all patients. Patients with CF have lower LBMI- $Z$ for BMI- $Z$ compared to controls. (B) The association between FMI- $Z$ and $\mathrm{BMI}-Z$ among healthy controls and patients with CF. There is a positive association between $\mathrm{BMI}-Z$ and $\mathrm{FMl}-Z$ in all patients that is not altered in the presence of CF. Circles represent data points for controls and the solid line represents the fitted line for controls. Crosses represent data points for CF patients and the dashed line represents the fitted line for CF subjects.

on AIC, LBMI- $Z$ was a better model than BMI- $Z$. Inclusion of FMI- $Z$ in the model with LBMI- $Z$ did not improve the model, and the association of FMI- $Z$ with $\mathrm{FEV}_{1} \%$-predicted remained insignificant $(p=0.18)$. No interaction was found between LBMI$Z$ and $\mathrm{BMI} \%$ category $(<50$ vs. $\geq 50 \%$ o $)$ in males $(p=0.68)$. Pubertal status did not alter the relationship of body composition with $\mathrm{FEV}_{1} \%$-predicted in this male $\mathrm{CF}$ population $(p=0.41)$.

After age adjustment, males with acceptable LBMI- $Z(\geq 0)$ were about five times more likely to have an $\mathrm{FEV}_{1} \%$-predicted $>80 \%$ than males with low LBMI- $Z(\mathrm{OR}=5.5, p=0.01)$. Males with acceptable BMI- $Z(\geq 0)$ were about four times more likely to have an $\mathrm{FEV}_{1} \%$-predicted $>80 \%(\mathrm{OR}=3.99, p=0.02)$ after adjustment for age.

Body mass index- $Z$ was also positively associated with ageadjusted $\mathrm{FVC} \%$-predicted in males (partial $\beta$-coefficient $=4.6$, $p=0.02$ ) after adjustment for age. Age-adjusted LBMI- $Z$ was positively associated with FVC\%-predicted ( $\operatorname{partial} \beta$-coefficient $=6.8$, $p<0.0001)$, but again FMI- $Z$ was not associated with $\mathrm{FVC} \%$ predicted $(p=0.16)$.
Table 2 | Association between BMI- $Z$ and (1) LBMI- $Z$ and (2) FMI- $Z$ in CF subjects $(n=208)$ and controls $(n=390)$ using linear regression.

\begin{tabular}{lllll}
\hline Predictor variable & $\begin{array}{l}\text { Partial } \beta \\
\text { coefficient }\end{array}$ & $95 \% \mathrm{Cl}$ & $p$-Value & $R^{2}$
\end{tabular}

\begin{tabular}{lcccc}
\hline \multicolumn{6}{l}{ OUTCOME VARIABLE: LEAN BODY MASS INDEX- $Z$} & & \\
Weight- $Z$ & 0.86 & $0.79,0.95$ & $<0.0001$ & 0.57 \\
Presence of CF & -0.04 & $-0.16,0.09$ & 0.5 & \\
Weight- $Z$ × presence of CF & -0.12 & $-0.25,0.01$ & 0.06 & \\
BMI- $Z$ & 0.94 & $0.89,0.99$ & $<0.0001$ & 0.69 \\
BMI- $Z$ & 0.92 & $0.86,0.97$ & $<0.0001$ & 0.70 \\
Presence of CF & -0.18 & $-0.28,-0.08$ & $<0.0001$ & \\
BMI- $Z$ & 0.92 & $0.85,0.98$ & $<0.0001$ & 0.70 \\
Presence of CF & -0.18 & $-0.28,-0.08$ & $<0.0001$ & \\
BMI- $Z$ × presence of CF & -0.00004 & $-0.11,0.11$ & 0.99 & \\
OUTCOME VARIABLE: FAT MASS INDEX-Z & & \\
Weight- $Z$ & 0.76 & $0.70,0.83$ & $<0.0001$ & 0.47 \\
Weight- $Z$ squared & 0.14 & $0.10,0.18$ & $<0.0001$ & \\
Presence of CF & 0.15 & $0.02,0.28$ & 0.024 & \\
BMI- $Z$ & 0.88 & $0.83,0.94$ & $<0.0001$ & 0.65 \\
BMI- $Z$ squared & 0.17 & $0.13,0.21$ & $<0.0001$ & \\
BMI- $Z$ & 0.89 & $0.84,0.94$ & $<0.0001$ & 0.65 \\
BMI- $Z$ squared & 0.17 & $0.13,0.22$ & $<0.0001$ & \\
Presence of CF & 0.06 & $-0.04,0.16$ & 0.24 & \\
\end{tabular}

\section{DISCUSSION}

Body mass index is typically used in the clinical care setting of CF to assess nutritional status. In this study of generally healthy youth with PI-CF, LBMI was more strongly associated with pulmonary function than BMI was (particularly in males), while FMI was not associated with pulmonary function. These findings support the hypothesis that the effect of better nutritional status in $\mathrm{CF}$ is mediated through muscle mass, not FM, and that the association of total body mass with pulmonary function in CF reflects an effect of LBM. However, CF is also associated with altered body composition: individuals with CF have lower LBM than otherwise healthy individuals with similar BMI- $Z$.

Lower LBM may result in respiratory muscle impairment of the diaphragm or accessory respiratory muscles and lead to poorer lung function $(8,23-25)$. Especially concerning would be the loss of muscles involved in coughing, e.g., abdominal musculature. Alternatively, chronic pulmonary inflammation and infection result in a catabolic state, and lower LBM may reflect worse lung disease (10). Systemic inflammation and malabsorption in $\mathrm{CF}$ lend to protein and muscle loss (26). Decreased muscle is compounded by decreased physical activity (27), inflammation (28), and chronic glucocorticoid therapy (29).

Visceral fat is thought to contribute to metabolic abnormalities by secreting inflammatory adipokines (30-33). A predisposition toward accumulating FM in preference to LBM may induce additional inflammation in CF patients. This study did not distinguish between visceral and subcutaneous fat, and, thus, this relationship of visceral fat to pulmonary function cannot be directly tested here.

Among individuals with moderate to severe CF lung disease, pancreatic insufficiency, and nutritional failure, improvements in 


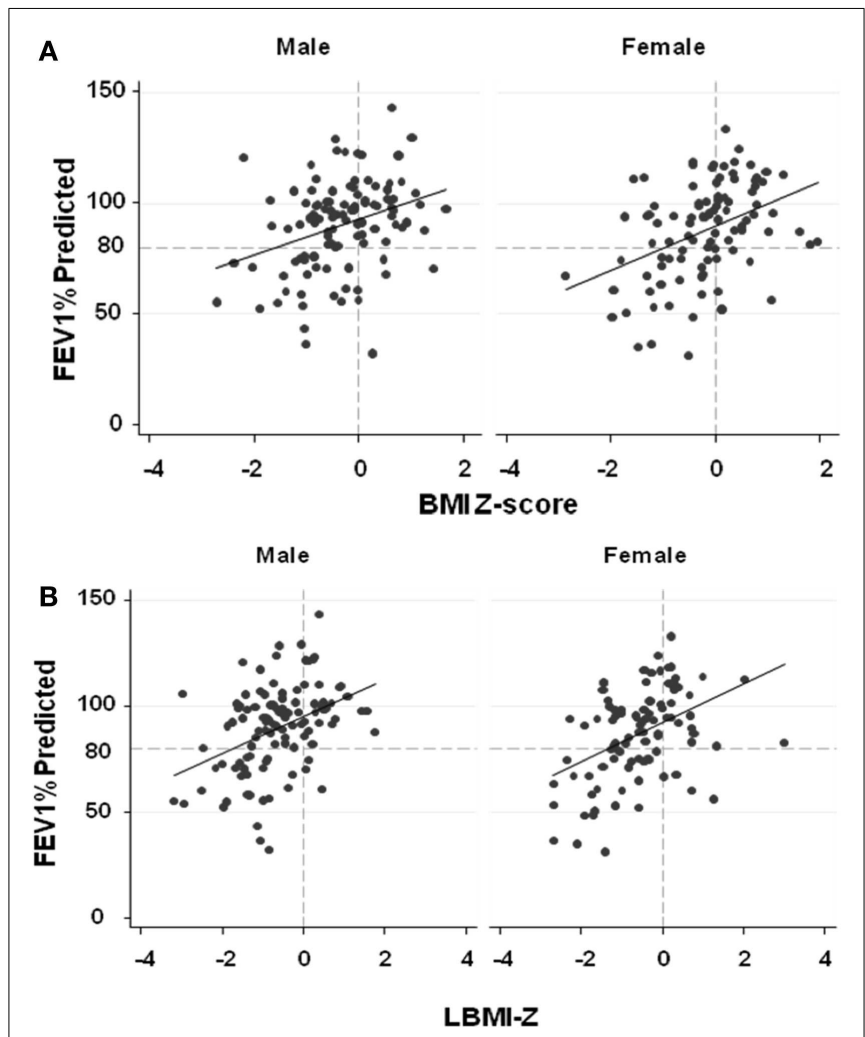

FIGURE 2 | (A) The associations between FEV1\%-predicted and BMI-Z adjusted for age among males and females with CF. BMI- $Z$ is positively associated with FEV1\%-predicted in males $(p<0.0001)$ and females $(p=0.001)$ with CF. (B) The association between FEV1\%-predicted and LBMI- $Z$ adjusted for age among males and females with CF. LBMI- $Z$ is positively associated with FEV $1 \%$-predicted in males $(p<0.0001)$ and females $(p<0.0001)$. (C) The association between FEV1\%-predicted and FMI- $Z$ adjusted for age among males and females with CF. No association between FEV1\%-predicted and FMI- $Z$ was found in males $(p=0.26)$ while FMI- $Z$ was positively associated with FEV1\%-predicted in females $(p=0.046)$ with CF.

nutritional status are associated with improved lung function (2, 34 ). The benefit of targeting $\mathrm{BMI} \geq 50 \%$ is clear, and predictive data from the logistic regression models in this study show a high likelihood of having normal lung function when BMI- $Z \geq 0$. Better expectations can be made for patients with LBMI- $Z \geq 0$.

In otherwise healthy individuals, increases in BMI at lower BMI generally reflect increases in LBM (35). This expected positive relationship between LBM and BMI seen in healthy individuals may be disrupted by inflammation in chronic illnesses (35). In our study, subjects with CF had lower LBMI- $Z$ compared to controls with similar BMI- $Z$. Moreover, subjects with CF had greater FMI- $Z$ compared to controls with similar Weight- $Z$, but this accumulation of fat over LBM was not reflected in our BMI- $Z$ models. Instead, the relationship between FM and BMI- $Z$ was similar to that observed in controls: curvilinear such that at BMI- $Z>1$, there is proportionately greater FM (36), a relationship that was not altered by the presence of CF.

Sex differences are also important. In females with BMI $<50$ th\%o, lower LBMI was associated with worse pulmonary
Table 3 | Relationship of body composition and pulmonary function in CF.

\begin{tabular}{|c|c|c|c|c|c|c|}
\hline Model & $\begin{array}{l}\text { Predictor } \\
\text { variable }\end{array}$ & $\begin{array}{l}\text { Partial } \beta \\
\text { coefficient }\end{array}$ & $p$-Value & $R^{2}$ & & AIC \\
\hline \multicolumn{7}{|c|}{ FEV $_{1} \%$ PREDICTED } \\
\hline \multirow[t]{14}{*}{ Females } & Age & -2.3 & $<0.0001$ & 0.34 & & 834 \\
\hline & BMI-Z & 7.5 & 0.001 & & & \\
\hline & Age & -2.4 & $<0.0001$ & 0.38 & & 811 \\
\hline & LBMI-Z & 8.0 & $<0.0001$ & & & \\
\hline & Age & -2.2 & $<0.0001$ & 0.44 & $\operatorname{LR} \chi^{2}=7.49$ & 806 \\
\hline & LBMI-Z & 11.7 & $<0.0001$ & & $p=0.006$ & \\
\hline & Optimal & -11.9 & 0.008 & & & \\
\hline & $\mathrm{BMI}^{\mathrm{a}} \times$ & & & & & \\
\hline & LBMI-Z & & & & & \\
\hline & Age & -2.4 & $<0.0001$ & 0.26 & & 827 \\
\hline & FMI-Z & 4 & 0.046 & & & \\
\hline & Age & -2.4 & $<0.0001$ & 0.37 & & 814 \\
\hline & LBMI-Z & 7.9 & $<0.0001$ & & & \\
\hline & $\mathrm{FMI}-Z$ & 0.1 & 0.96 & & & \\
\hline \multirow[t]{18}{*}{ Males } & Age & 9.46 & 0.004 & 0.23 & & 960 \\
\hline & $\mathrm{Age}^{2}$ & -0.42 & 0.001 & & & \\
\hline & BMI-Z & 7.8 & $<0.0001$ & & & \\
\hline & Age & 11.78 & $<0.0001$ & 0.32 & & 928 \\
\hline & $\mathrm{Age}^{2}$ & -0.51 & $<0.0001$ & & & \\
\hline & LBMI-Z & 9.77 & $<0.0001$ & & & \\
\hline & Age & 12.03 & $<0.0001$ & 0.31 & $\operatorname{LR} \chi^{2}=0.18$ & 932 \\
\hline & $\mathrm{Age}^{2}$ & -0.52 & $<0.0001$ & & $p=0.67$ & \\
\hline & Optimal & -2.2 & 0.68 & & & \\
\hline & $\mathrm{BMI}^{\mathrm{a}} \times$ & & & & & \\
\hline & LBMI-Z & & & & & \\
\hline & Age & 8.85 & 0.013 & 0.12 & & 967 \\
\hline & $\mathrm{Age}^{2}$ & -0.39 & 0.004 & & & \\
\hline & $\mathrm{FMI}-Z$ & -2.32 & 0.28 & & & \\
\hline & Age & 11.67 & $<0.0001$ & 0.33 & & 929 \\
\hline & $\mathrm{Age}^{2}$ & -0.50 & $<0.0001$ & & & \\
\hline & LBMI-Z & 9.80 & $<0.0001$ & & & \\
\hline & FMI-Z & -2.48 & 0.18 & & & \\
\hline
\end{tabular}

${ }^{a} \mathrm{BMI}$ less than (or) greater than or equal to 50 percentile.

function, whereas lower LBMI was associated with worse pulmonary function in males regardless of whether BMI was greater than or less than 50 th\%o. For two males with the same BMI, the male with lower LBM will have lower pulmonary function regardless of whether or not the BMI is in the recommended $\geq 50$ th $\%$ o range (Table 2 ). In females, then, focusing on intervening in patients with $\mathrm{BMI}<50$ th\%o appears particularly relevant (Table 2). In contrast, focusing on males with $\mathrm{BMI}<50 \%$ may miss an important target group in the acceptable $\mathrm{BMI}$ range.

Accrual of lean muscle mass is the logical aim of nutritional and physical therapies. Aerobic fitness and survival in CF correlate closely (37) and exercise training and habitual physical activity improve muscle strength $(38,39)$, quality of life $(40)$, and mucus clearance (41). The extent to which physical activity impacted body 
composition and pulmonary function in the subjects in this study was not explored.

Changes in body composition occur in males and females during puberty (42). Males predominantly gain FFM while females gain FM. In males, less LBM might reflect less physical activity, worse disease, or lower androgen effect, all of which may result from CF disease (43). However, our findings persisted even after adjustment of our models for puberty in both males and females.

The extent to which the results of this cross-sectional study of a relatively healthy CF population (mean $\mathrm{FEV}_{1} \%$-predicted $89 \pm 21$ ) can be generalized to CF patients with poor lung function and co-morbidities including severe liver disease and CF-related diabetes is not clear. Additionally, longitudinal data are needed to assess the temporal relationship between LBM and lung function and to examine LBM and FM accrual in CF. Until recently, indices for FM and LBM have been unavailable outside the research setting. Wells et al. recently published new body composition reference data for DXA and the four-compartment model (44), and Weber et al. published LMI and FMI reference data based upon a sample from NHANES (45). The availability of this reference data may permit extension of these measures to the clinical setting.

Dual x-ray absorptiometry scanning is becoming increasingly appealing due to widespread availability, its accuracy in measurements $(46,47)$, and non-invasive nature. The 2005 Cystic Fibrosis Foundation Consensus Conference (48) recommends screening for decreased bone mineral density using DXA on select patients. While these recommendations are targeted to assess bone structure and health, in certain individuals, especially underweight females and males with low lung function suspected to be due to poor nutrition, assessing LBM via DXA may identify LBM depletion and could guide appropriate interventions. Recommendations for obtaining screening DXA scans to assess body composition will require more definitive longitudinal data that support its utility over anthropometry alone. Furthermore, large studies examining the effects of interventions on body composition are needed to pave the way for guidelines regarding the CF population at risk for fat and LBM deficits. At this time, BMI remains a good reflection of nutritional status although it may not fully depict the altered body composition we identified in CF.

In conclusion, we confirm that LBMI- $Z$ is associated with $\mathrm{FEV}_{1} \%$-predicted and that LBM is lower than one would expect for a given BMI. Thus, while BMI remains an adequate screening tool in CF patients, determination of LBM may be useful for assessing the relationship of body composition to pulmonary function particularly at lower BMI and in the clinical research setting; future interventions in CF may better examine the impact upon LBM with the use of DXA.

\section{ACKNOWLEDGMENTS}

We are indebted to our collaborators at the CF Centers at The Hershey Medical Center, Hershey, PA, USA; Children's National Medical Center, Washington, DC, USA; Monmouth Medical Center, Long Branch, NJ, USA; The Pediatric Lung Center (Fairfax Neonatal Associates, PC), Fairfax, VA, USA; Cystic Fibrosis Center of University of Virginia, Charlottesville, VA, USA; Children's Hospital of the King's Daughters, Eastern Virginia Medical School, Norfolk, VA, USA; Yale University School of Medicine, New Haven,
CT, USA; Schneider Children's Hospital, North Shore Island Jewish Health System, New Hyde Park, NY, USA; St. Joseph's Children's Hospital, Paterson, NJ, USA; and The Pediatric Specialty Center at Lehigh Valley Hospital, Bethlehem, PA, USA. In particular we acknowledge Drs. Joan Schall, Maria Mascarenhas, Asim Maqbool, John Osbron, and Ms. Sandy Robbins. Source(s) of support: NIDDK (R44 DK060302), Cystic Fibrosis Foundation, the University of Pennsylvania and Children's Hospital of Philadelphia Clinical and Translational Research Center (NIH/NCATS UL1TR000003), Children's Hospital of Philadelphia Nutrition Center.

\section{REFERENCES}

1. Corey M, McLaughlin FJ, Williams M, Levison H. A comparison of survival, growth, and pulmonary function in patients with cystic fibrosis in Boston and Toronto. J Clin Epidemiol (1988) 41(6):583-91. doi:10.1016/0895-4356(88) 90063-7

2. Zemel BS, Jawad AF, FitzSimmons S, Stallings VA. Longitudinal relationship among growth, nutritional status, and pulmonary function in children with cystic fibrosis: analysis of the cystic fibrosis foundation national CF patient registry. J Pediatr (2000) 137(3):374-80. doi:10.1067/mpd.2000.107891

3. Sharma R, Florea VG, Bolger AP, Doehner W, Florea ND, Coats AJ, et al. Wasting as an independent predictor of mortality in patients with cystic fibrosis. Thorax (2001) 56(10):746-50. doi:10.1136/thorax.56.10.746

4. Stallings VA, Stark LJ, Robinson KA, Feranchak AP, Quinton H. Evidence-based practice recommendations for nutrition-related management of children and adults with cystic fibrosis and pancreatic insufficiency: results of a systematic review. J Am Diet Assoc (2008) 108(5):832-9. doi:10.1016/j.jada.2008.02.020

5. King SJ, Nyulasi IB, Strauss BJ, Kotsimbos T, Bailey M, Wilson JW. Fatfree mass depletion in cystic fibrosis: associated with lung disease severity but poorly detected by body mass index. Nutrition (2010) 26(7-8):753-9. doi:10.1016/j.nut.2009.06.026

6. Pedreira CC, Robert RG, Dalton V, Oliver MR, Carlin JB, Robinson P, et al. Association of body composition and lung function in children with cystic fibrosis. Pediatr Pulmonol (2005) 39(3):276-80. doi:10.1002/ppul.20162

7. Rochat T, Slosman DO, Pichard C, Belli DC. Body composition analysis by dual-energy x-ray absorptiometry in adults with cystic fibrosis. Chest (1994) 106(3):800-5. doi:10.1378/chest.106.3.800

8. Enright S, Chatham K, Ionescu AA, Unnithan VB, Shale DJ. The influence of body composition on respiratory muscle, lung function and diaphragm thickness in adults with cystic fibrosis. J Cyst Fibros (2007) 6(6):384-90. doi:10.1016/j.jcf.2007.02.006

9. Bolton CE, Ionescu AA, Evans WD, Pettit RJ, Shale DJ. Altered tissue distribution in adults with cystic fibrosis. Thorax (2003) 58(10):885-9. doi:10.1136/thorax. 58.10 .885

10. Ionescu AA, Nixon LS, Luzio S, Lewis-Jenkins V, Evans WD, Stone MD, et al. Pulmonary function, body composition, and protein catabolism in adults with cystic fibrosis. Am J Respir Crit Care Med (2002) 165(4):495-500. doi:10.1164/ ajrccm.165.4.2104065

11. Engelen MP, Schroder R, Van der Hoorn K, Deutz NE, Com G. Use of body mass index percentile to identify fat-free mass depletion in children with cystic fibrosis. Clin Nutr (2012) 31(6):927-33. doi:10.1016/j.clnu.2012.04.012

12. Ionescu AA, Evans WD, Pettit RJ, Nixon LS, Stone MD, Shale DJ. Hidden depletion of fat-free mass and bone mineral density in adults with cystic fibrosis. Chest (2003) 124(6):2220-8. doi:10.1378/chest.124.6.2220

13. Sood M, Adams JE, Mughal MZ. Lean body mass in children with cystic fibrosis. Arch Dis Child (2003) 88(9):836. doi:10.1136/adc.88.9.836-a

14. Williams JE, Wells JC, Benden C, Jaffe A, Suri R, Wilson CM, et al. Body composition assessed by the 4-component model and association with lung function in 6-12-y-old children with cystic fibrosis. Am J Clin Nutr (2010) 92(6):1332-43. doi:10.3945/ajcn.2010.29847

15. Kastner-Cole D, Palmer CN, Ogston SA, Mehta A, Mukhopadhyay S. Overweight and obesity in deltaF508 homozygous cystic fibrosis. J Pediatr (2005) 147(3):402-4. doi:10.1016/j.jpeds.2005.06.003

16. Kelly A, Schall JI, Stallings VA, Zemel BS. Deficits in bone mineral content in children and adolescents with cystic fibrosis are related to height deficits. J Clin Densitom (2008) 11(4):581-9. doi:10.1016/j.jocd.2008.07.002 
17. Thayu M, Denson LA, Shults J, Zemel BS, Burnham JM, Baldassano RN, et al. Determinants of changes in linear growth and body composition in incident pediatric Crohn's disease. Gastroenterology (2010) 139(2):430-8. doi:10.1053/j. gastro.2010.04.044

18. Kuczmarski RJ, Ogden CL, Grummer-Strawn LM, Flegal KM, Guo SS, Wei R, et al. CDC growth charts: United States. Adv Data (2000) 8(314):1-27.

19. Schall JI, Semeao EJ, Stallings VA, Zemel BS. Self-assessment of sexual maturity status in children with Crohn's disease. J Pediatr (2002) 141(2):223-9. doi: $10.1067 / \mathrm{mpd} .2002 .125907$

20. Pan H, Cole T, Schartmaker LM. A Program to Construct Growth Reference Data Using the LMS Method, Version 2.43 (2010). Available from: http: //www.healthforallchildren.co.uk

21. Wang X, Dockery DW, Wypij D, Fay ME, Ferris BG Jr. Pulmonary function between 6 and 18 years of age. Pediatr Pulmonol (1993) 15(2):75-88. doi:10.1002/ppul.1950150204

22. Hankinson JL, Odencrantz JR, Fedan KB. Spirometric reference values from a sample of the general U.S. population. Am J Respir Crit Care Med (1999) 159(1):179-87. doi:10.1164/ajrccm.159.1.9712108

23. Lazarus R, Gore CJ, Booth M, Owen N. Effects of body composition and fat distribution on ventilatory function in adults. Am J Clin Nutr (1998) 68(1):35-41.

24. Mohamed EI, Maiolo C, Iacopino L, Pepe M, Di Daniele N, De Lorenzo A. The impact of body-weight components on forced spirometry in healthy Italians. Lung (2002) 180(3):149-59. doi:10.1007/s004080000089

25. Ionescu AA, Chatham K, Davies CA, Nixon LS, Enright S, Shale DJ. Inspiratory muscle function and body composition in cystic fibrosis. Am J Respir Crit Care Med (1998) 158(4):1271-6. doi:10.1164/ajrccm.158.4.9710079

26. Bell SC, Bowerman AM, Nixon LE, Macdonald IA, Elborn JS, Shale DJ. Metabolic and inflammatory responses to pulmonary exacerbation in adults with cystic fibrosis. Eur J Clin Invest (2000) 30(6):553-9. doi:10.1046/j.1365-2362. 2000.00667.x

27. Kortebein P, Ferrando A, Lombeida J, Wolfe R, Evans WJ. Effect of 10 days of bed rest on skeletal muscle in healthy older adults. JAMA (2007) 297(16):1772-4. doi:10.1001/jama.297.16.1772-b

28. Drey M. Sarcopenia - pathophysiology and clinical relevance. Wien Med Wochenschr (2011) 161(17-18):402-8. doi:10.1007/s10354-011-0002-y

29. Barry SC, Gallagher CG. Corticosteroids and skeletal muscle function in cystic fibrosis. J Appl Physiol (2003) 95(4):1379-84. doi:10.1152/japplphysiol.00506. 2002

30. Fried SK, Bunkin DA, Greenberg AS. Omental and subcutaneous adipose tissues of obese subjects release interleukin-6: depot difference and regulation by glucocorticoid. J Clin Endocrinol Metab (1998) 83(3):847-50. doi:10.1210/jc.83.3.847

31. Tchernof A, Despres JP. Pathophysiology of human visceral obesity: an update. Physiol Rev (2013) 93(1):359-404. doi:10.1152/physrev.00033.2011

32. Cartier A, Cote M, Bergeron J, Almeras N, Tremblay A, Lemieux I, et al. Plasma soluble tumour necrosis factor-alpha receptor 2 is elevated in obesity: specific contribution of visceral adiposity. Clin Endocrinol (Oxf) (2010) 72(3):349-57. doi:10.1111/j.1365-2265.2009.03671.x

33. Fontana L, Eagon JC, Trujillo ME, Scherer PE, Klein S. Visceral fat adipokine secretion is associated with systemic inflammation in obese humans. Diabetes (2007) 56(4):1010-3. doi:10.2337/db06-1656

34. Milla CE. Association of nutritional status and pulmonary function in children with cystic fibrosis. Curr Opin Pulm Med (2004) 10(6):505-9. doi:10.1097/01. mcp.0000138995.08494.69

35. Demerath EW, Schubert CM, Maynard LM, Sun SS, Chumlea WC, Pickoff A, et al. Do changes in body mass index percentile reflect changes in body composition in children? Data from the Fels Longitudinal Study. Pediatrics (2006) 117(3):e487-95. doi:10.1542/peds.2005-0572

36. Freedman DS, Wang J, Maynard LM, Thornton JC, Mei Z, Pierson RN, et al. Relation of BMI to fat and fat-free mass among children and adolescents. Int J Obes (Lond) (2005) 29(1):1-8. doi:10.1038/sj.ijo.0802735
37. Coates AL, Boyce P, Muller D, Mearns M, Godfrey S. The role of nutritional status, airway obstruction, hypoxia, and abnormalities in serum lipid composition in limiting exercise tolerance in children with cystic fibrosis. Acta Paediatr Scand (1980) 69(3):353-8. doi:10.1111/j.1651-2227.1980.tb07092.x

38. Selvadurai HC, Blimkie CJ, Meyers N, Mellis CM, Cooper PJ, Van Asperen PP. Randomized controlled study of in-hospital exercise training programs in children with cystic fibrosis. Pediatr Pulmonol (2002) 33(3):194-200. doi:10.1002/ ppul.10015

39. Orenstein DM, Hovell MF, Mulvihill M, Keating KK, Hofstetter CR, Kelsey S, et al. Strength vs aerobic training in children with cystic fibrosis: a randomized controlled trial. Chest (2004) 126(4):1204-14. doi:10.1378/chest.126.4.1204

40. Klijn PH, Oudshoorn A, van der Ent CK, van der Net J, Kimpen JL, Helders PJ. Effects of anaerobic training in children with cystic fibrosis: a randomized controlled study. Chest (2004) 125(4):1299-305. doi:10.1378/chest. 125.4.1299

41. Baldwin DR, Hill AL, Peckham DG, Knox AJ. Effect of addition of exercise to chest physiotherapy on sputum expectoration and lung function in adults with cystic fibrosis. Respir Med (1994) 88(1):49-53. doi:10.1016/0954-6111(94) 90174-0

42. Loomba-Albrecht LA, Styne DM. Effect of puberty on body composition. Curr Opin Endocrinol Diabetes Obes (2009) 16(1):10-5. doi:10.1097/MED. 0b013e328320d54c

43. Landon C, Rosenfeld RG. Short stature and pubertal delay in cystic fibrosis. Pediatrician (1987) 14(4):253-60.

44. Wells JC, Williams JE, Chomtho S, Darch T, Grijalva-Eternod C, Kennedy K, et al. Body-composition reference data for simple and reference techniques and a 4-component model: a new UK reference child. Am J Clin Nutr (2012) 96(6):1316-26. doi:10.3945/ajcn.112.036970

45. Weber DR, Moore RH, Leonard MB, Zemel BS. Fat and lean BMI reference curves in children and adolescents and their utility in identifying excess adiposity compared with BMI and percentage body fat. Am J Clin Nutr (2013) 98(1):49-56. doi:10.3945/ajcn.112.053611

46. Mazess RB, Barden HS, Bisek JP, Hanson J. Dual-energy x-ray absorptiometry for total-body and regional bone-mineral and soft-tissue composition. Am JClin Nutr (1990) 51(6):1106-12.

47. Slosman DO, Casez JP, Pichard C, Rochat T, Fery F, Rizzoli R, et al. Assessment of whole-body composition with dual-energy x-ray absorptiometry. Radiology (1992) 185(2):593-8.

48. Aris RM, Merkel PA, Bachrach LK, Borowitz DS, Boyle MP, Elkin SL, et al. Guide to bone health and disease in cystic fibrosis. J Clin Endocrinol Metab (2005) 90(3):1888-96. doi:10.1210/jc.2004- 1629

Conflict of Interest Statement: The authors declare that the research was conducted in the absence of any commercial or financial relationships that could be construed as a potential conflict of interest.

Received: 24 January 2014; paper pending published: 27 March 2014; accepted: 02 April 2014; published online: 15 April 2014.

Citation: Sheikh S, Zemel BS, Stallings VA, Rubenstein RC and Kelly A (2014) Body composition and pulmonary function in cystic fibrosis. Front. Pediatr. 2:33. doi: 10.3389/fped.2014.00033

This article was submitted to Pediatric Pulmonology, a section of the journal Frontiers in Pediatrics.

Copyright (c) 2014 Sheikh, Zemel, Stallings, Rubenstein and Kelly. This is an openaccess article distributed under the terms of the Creative Commons Attribution License (CC BY). The use, distribution or reproduction in other forums is permitted, provided the original author(s) or licensor are credited and that the original publication in this journal is cited, in accordance with accepted academic practice. No use, distribution or reproduction is permitted which does not comply with these terms. 